\title{
AN INTUITIONISTIC FUZZY-TODIM METHOD TO SOLVE DISTRIBUTOR EVALUATION AND SELECTION PROBLEM
}

\author{
Li, M. ${ }^{* * *} ; \mathrm{Wu}, \mathrm{C}^{*}{ }^{* \#} ;$ Zhang, L. ${ }^{* * *} \&$ You, L.-N. ${ }^{* * * *}$ \\ ${ }^{*}$ School of Management, Harbin Institute of Technology, Harbin, 150001, China \\ ${ }^{* *}$ School of Logistics Management and Engineering, Guangxi Teachers Education University, \\ Nanning, 530001, China \\ *** College of Business Administration, Zhejiang University of Finance and Economics, Hangzhou, \\ 310018, China \\ ${ }^{* * * *}$ China Mobile Guangxi Company, Nanning, 530022, China \\ E-Mail: shmilylm@sina.com, wuchong@hit.edu.cn ( ${ }^{\#}$ Corresponding author)
}

\begin{abstract}
In the collaborative planning, forecasting and replenishment (CPFR) process of supply chain management, the distributor is the leading "tie" between manufacturer and customer, a key figure in collecting marketing information, reducing the demand uncertainty and improving customer satisfaction. In the CPFR process, by making reasonable evaluations and selections the distributors can ensure smooth distribution channels and enhance the competitiveness of the entire supply chain. As a result, distributor evaluation and selection is a pivotal step in the process of supply chain management. In order to improve the validity and reliability of the evaluation and selection model, this paper proposes a decision model based on Intuitionistic Fuzzy-TODIM (IF-TODIM) and carries out example calculation and simulation analysis. Firstly, the CPFR process of the existing supply chain management method and the evaluation indicator system of the distributors were analysed. The next stage was to establish a selection criteria system (which the CPFR process requires) and then create an evaluation model based on the IF-TODIM selection model and prospect theory. Uncertainty and risk aversion were full considered in the distributor evaluation and selection model for the manufacturers. Finally an example calculation process and the simulation analysis revealed that the model displayed operability and effectiveness, can effectively solve the problem of distributor selection under uncertainty condition and help manufacturers determine the optimal distributor partners quickly, at the same time maximizing the choice of avoiding enterprise risk.

(Received, processed and accepted by the Chinese Representative Office.)
\end{abstract}

Key Words: Distributor Evaluation and Selection, Evaluation and Selection Indicator System, Intuitionistic Fuzzy Set, TODIM, Prospect Theory

\section{INTRODUCTION}

Collaborative planning, forecasting and replenishment (CPFR) is a new method of supply chain management. By means of collaborative management of business and information sharing, manufacturers can improve the partnership with distributors and suppliers, enhancing the accuracy of demand forecasting by narrowing the differences between the demand and supply. This eventually leads to improvements in supply chain efficiency, reducing inventory and promoting customer satisfaction.

In the CPFR process for the core manufacturing enterprises, distributor evaluation and supplier selection both occupy very important positions. This thesis focuses on the former. Firstly, distributors, as the primary "tie" between manufacturers and customers, are closer to the downstream customers than manufacturers. They collect marketing information and work as the information centre in the CPFR process. Manufacturers operate at a distance from customers, and so are not sensitive enough to changes in the market, thus can only rely on distributors to establish a forecasting system to reduce the demand uncertainty and decrease the bullwhip effect. Secondly, distributors are the service provider and have greater contact 
with customers. This allows them direct reflecting the service level of the supply chain and places them at the influential core for customer satisfaction. Distributor management includes distributor evaluation and selection, incentive and performance assessment. The method used to evaluate and select the distributors occupies a very important position and is the foundation of distributor management. Therefore, reasonable evaluation and selection to the distributors can ensure smooth distribution channels in the CPFR process, so that the competitiveness of the whole supply chain can be increased.

At present, a large number of studies on distributor evaluation and selection that have been carried out by scholars are mainly in two categories. The first category is about developing selection criteria and indicators, the other is to construct the selection method and model. In the evaluation indicator system research, the earliest specialist Berndel, designed 20 indicators to select channel members for the industrial goods (not consumer goods) production enterprises. The core indicator for the distributor was the sales level. The study still has a realistic significance today [1]. The distributor evaluation and selection criteria proposed by Pegram in the 1960s are regarded as the most comprehensive and the most influential. He carried out empirical analysis on more than 200 manufacturers in the United States and Canada, condensed to just 10 indicators to select the channel member, including product line, market coverage, continuity of management and other creative ones [1]. From then on, many scholars have carried out further research on distributor evaluation indicators. Mohr and Nevin [2] deemed satisfaction and sales as the key indicators. Jonsson and Zineldin [3] proposed a conceptual model based on the behaviour relationship between suppliers and distributors, which shows that a good reputation and a close relationship are the key variables to keep long-term cooperation and trust between enterprises. Lin and Chen [4] focused on marketing, supply chain, and logistics literature, investigating their influences. The method and modelling of the distributor evaluation and selection is similar to that of the supplier selection and cooperative partner selection, all of which are mainly focused on the fuzzy inference method [5], the knowledge based system method [6-7], the rough set theory method [8], the neural network [9], the hybrid method [10-12] and so on.

So far, the research on a distributor evaluation indicator system and selection method has made substantial progress. The evaluation index is no longer limited to several mandatory indexes such as sales and market share, and pays more attention to the soft power such as supply chain coordination development. Distributor selection method research has experienced periods of growth in the amount of quantitative and qualitative research as well as some combined research. It is no longer limited to a single evaluation method but makes use of the advantages of all methods so as to reduce the limitations, which in turn makes the results more credible and the application range wider. However, there are still some shortcomings in the current evaluation system and selection decision model which are mainly manifested in the following two aspects:

(1) The distributor selection method doesn't take the possibility of change of the decision-makers' subjective evaluation into account. In fact during the selection process, quantitative data and qualitative data usually need to be dealt with at the same time. Even the uncertain data information can have an effect on decision making because the selection criteria and attributes can't be quantitative and there is also some influence from decisionmakers' subjective factors. At present, a lot of research scholars have turned to the uncertainty field using rough set or fuzzy set theory to deal with the impact of uncertainty information on decision making. However, the rough set theory requires discrete data with large sample sizes and strong statistical rules, so the calculation is large and it's easy to fail to extract the decision rules. Fuzzy set theory deals with the vagueness by the membership function, which takes the compliance of the distributors' actual situation into account to evaluate the enterprises expected value, but without considering the possibility of uncertainty and change 
that is produced by decision-makers' subjective evaluation, so there are further improvements to be made.

(2) Distributor evaluation and selection process is often based on supply chain coordination mechanism (CPFR process is one of them). Thus the decision-makers with manufacturing enterprises as the core often have psychological behaviours such as relying on reference and risks aversion for benefit maximization and long-term partnerships. So far, none of the existing models for distributor evaluation have considered these psychological factors.

In this paper, the problem of distributor evaluation and selection based on the Intuitionistic Fuzzy TODIM method using the CPFR process was studied. Intuitionistic fuzzy theory can not only describe the compliance and difference of the distributor actual performance with manufacturers expectation, but also can describe the possibility of the decision-makers' neutral and hesitant attitude, leading to a more scientific evaluation of the distributors' actual performance from two categories. Besides, because of its natural data characteristics intuitionistic fuzzy number doesn't need to be standardized, so the calculation workload is greatly reduced. For the evaluation method, this paper selected the TODIM method based on prospect theory, which: fully considered psychological behaviours of the decision makers and constructed a pairwise comparison matrix for the evaluated distributors to determine each dominance degree for further comparison; made simulation analysis by the variation of loss aversion parameter; and obtained decision makers evaluation results under different risk preferences. Through the decision model based on IF-TODIM, the distributor evaluation and selection becomes more scientific, objective and easily operated.

\section{DISTRIBUTOR EVALUATION AND SELECTION SYSTEM BY THE CPFR PROCESS}

\subsection{CPFR model based on supply chain}

Based on CFAR (Collaborative Forecast And Replenishment), CPFR is designed for further promotion of the collaborative planning of the enterprises in the supply chain. Cooperative enterprises not only implement collaborative forecasting and replenishment, but also share their internal plan work (e.g., production planning, inventory planning, distribution planning, marketing planning, etc.) in the supply chain network and invite other cooperative enterprises to participate into the process of plan formulation and implementation. This successfully makes use of the Internet to achieve cooperation across the supply chain members and provides better forecasting, planning and replenishment with the shared information resources.

In CPFR, the main work includes four aspects:

(1) Collaboration: Only when the upstream and downstream enterprises in the supply chain establish a common goal, can the overall performance be improved and the comprehensive benefits can be achieved.

(2) Planning: To achieve the common goal, the enterprises in the supply chain need to make collaborative planning including product promotion, inventory change policy, product import, termination policy, sales activity and storage classification, etc.

(3) Forecasting: It is important to make collaborative forecasts for the buyers and the sellers in CPFR, because in this way it is possible to significantly reduce the low efficiency and the dead inventory, promote product sales and economically use the resources of the whole supply chain. At the same time, it proves that the cooperative promotion plan is the key to improving the prediction accuracy. The key factor attributed to improving the forecasting accuracy is implementing the collaborative product promotion planning. The collaborative forecasting in CPFR requires each enterprise not only to make a final forecast, but also to participate in the information process feedback from the forecasting. 
(4) Replenishment: The upstream and downstream enterprises in the supply chain should replenish in time according to the forecast sales system and the supply-side constraints. These include order processing cycles, lead time and minimum order, and the two kinds of enterprises should consult mutually as early as possible when exceptions appear.

According to the main characteristic of CPFR, the supply chain model based on CPFR is designed as shown in Fig. 1 below.

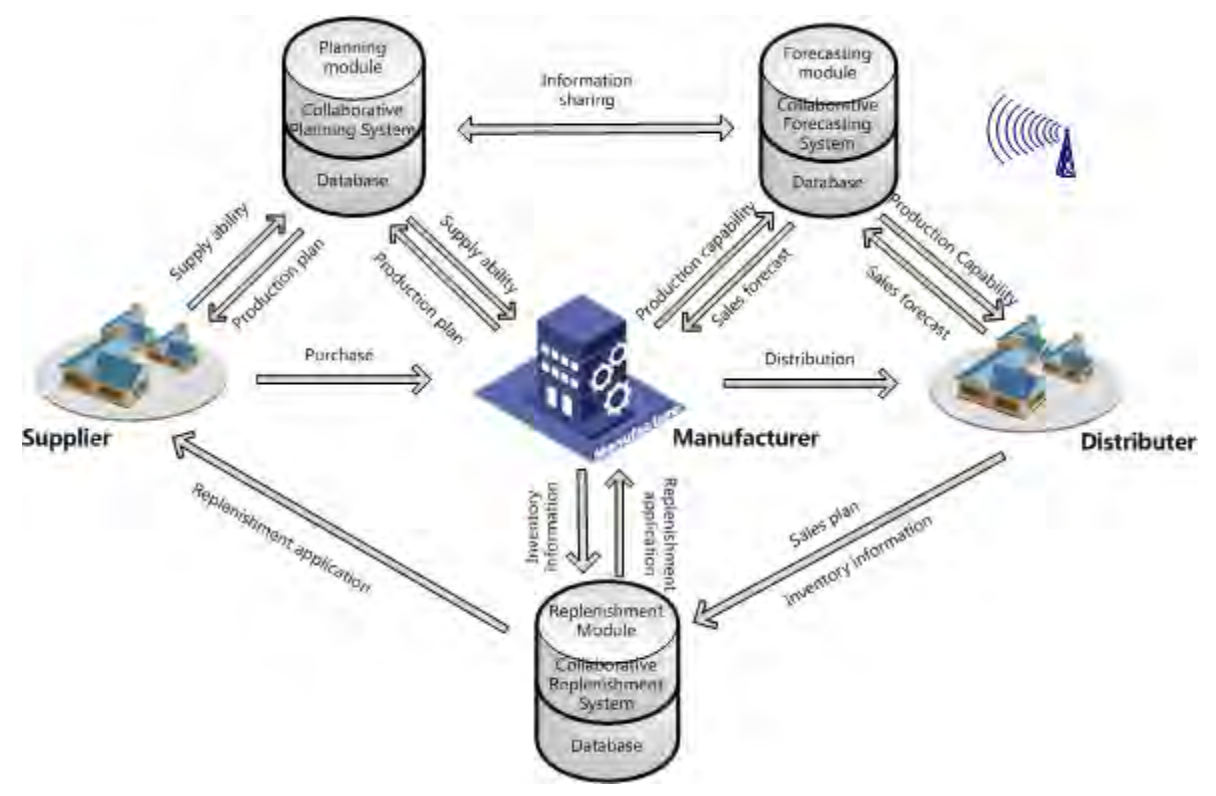

Figure 1: The supply chain model based on CPFR.

\subsection{The indicator system of the distributor evaluation and selection}

From the CPFR supply chain model above, we can see that distributors are connected to the manufacturers through collaborative forecasting and replenishment models and are customer/marketing facing. Manufacturers, as the supply chain core, should consider not only the traditional indicators such as the logistics capability, marketing and customer service level, but also the collaboration ability in the distributor evaluation and selection. Selecting the appropriate distributors and establishing close long-term relations based on cooperation can decrease supply chain cost, reduce inventory, increase cash flow, as well as develop long-term supply chain coordination and sustainability.

Through researching and analysing a large number of literatures and combining this with the overall requirements of the CPFR process for distributors as well as expert opinions, we established 25 specific indicators and further integrated them into six overall indicators $\left(C_{1^{-}}\right.$ $C_{6}$ ), including the distributor's core business ability and collaborative development ability. Due to the large number of indicators, in order to facilitate the expert score rapidly, accurately and comprehensively, we designed the distributor evaluation and selection indicator system which is shown in Table I.

\section{DISTRIBUTOR EVALUATION AND SELECTION MODEL BASED ON IF-TODIM}

\subsection{The basic theory of the intuitionistic fuzzy set and distance measure formula}

The intuitionistic fuzzy set is an extension of Atanassov [13, 14] to Zadeh [15] traditional fuzzy set theory and it can process fuzzy information better. The intuitionistic fuzzy set is very effective in the application of the evaluation problem and it can be used to describe the 
fuzzy nature of information, so that the evaluation of the uncertainty information is more expressive.

Table I: The distributor evaluation and selection indicator system based on the CPFR process.

\begin{tabular}{|l|l|}
\hline \multicolumn{2}{|c|}{ Distributor core business ability } \\
\hline Finance situation $\boldsymbol{C}_{\mathbf{1}}$ & Ratio of sales $C_{11}$ \\
\hline & Current ratio $C_{12}$ \\
\hline & Quick ratio $C_{13}$ \\
\hline & Asset-liability Ratio $C_{14}$ \\
\hline Market ability $\boldsymbol{C}_{\mathbf{2}}$ & Inventory turnover $C_{15}$ \\
\hline & Volume of sales $C_{21}$ \\
\hline & Market share $C_{22}$ \\
\hline Logistics capability $\boldsymbol{C}_{\mathbf{3}}$ & Site coverage $C_{23}$ \\
\hline & Timeliness of delivery $C_{31}$ \\
\hline & Accuracy of delivery $C_{32}$ \\
\hline & Effectiveness of delivery $C_{33}$ \\
\hline Customer service ability $\boldsymbol{C}_{\mathbf{4}}$ & Logistics infrastructure $C_{34}$ \\
\hline & Customer satisfaction $C_{41}$ \\
\hline \multicolumn{2}{|c|}{ Collaborative development ability } \\
\hline Informatization level and information sharing $\boldsymbol{C}_{\mathbf{5}}$ & Informatization level of assembly $C_{51}$ \\
\hline & Information technology personnel quality $C_{52}$ \\
\hline & Information sharing level $C_{53}$ \\
\hline Integration and cooperation intention $\boldsymbol{C}_{\mathbf{6}}$ & Information feedback speed $C_{54}$ \\
\hline & Enterprise culture $C_{61}$ \\
\hline & Quality of employees $C_{62}$ \\
\hline & Management level $C_{63}$ \\
\hline & Compatibility with supply chain enterprises $C_{64}$ \\
\hline & Cooperation initiative $C_{65}$ \\
\hline & Corporate reputation and influence $C_{66}$ \\
\hline
\end{tabular}

Definition 1: [13] Suppose $X$ is a non-empty set and the intuitionistic fuzzy set $A$ on the domain $X$ is defined as following:

$$
A=\left\{\left\langle x, \mu_{A}(x), v_{A}(x)\right\rangle \mid x \in X\right\}
$$

where $\mu_{A}(x)$ and $v_{A}(x)$ denote respectively the degrees of membership and non-membership that element $x$ belonged to $A$ on $X$, i.e. $\mu_{A}: X \rightarrow[0,1], x \in X \rightarrow \mu_{A}(x) \in[0,1], v_{A}: X \rightarrow[0,1]$, $x \in X \rightarrow v_{A}(x) \in[0,1]$ and $0 \leq \mu_{A}(x)+v_{A}(x) \leq 1$; then $\pi_{A}=1-\mu_{A}(x)-v_{A}(x)$ is called the degree of hesitation or uncertainty that element $x$ belonged to $A$ on $X$. Obviously, for any $x \in X$, $0 \leq \pi_{A}(x) \leq 1$. Some basic operations of intuitionistic fuzzy sets are shown in Definition 2.

Definition 2: [16] If $\alpha=\left(\mu_{\alpha}, v_{\alpha}\right), \alpha_{1}=\left(\mu_{\alpha_{1}}, v_{\alpha_{1}}\right)$ and $\alpha_{2}=\left(\mu_{\alpha_{2}}, v_{\alpha_{2}}\right)$ are all intuitionistic fuzzy numbers, then
(1) $\bar{\alpha}=\left(v_{\alpha}, \mu_{\alpha}\right)$;
(2) $\alpha_{1} \wedge \alpha_{2}=\left\{\min \left(\mu_{\alpha_{1}}, \mu_{\alpha_{2}}\right), \max \left(v_{\alpha_{1}}, v_{\alpha_{2}}\right)\right\}$;
(3) $\alpha_{1} \vee \alpha_{2}=\left\{\max \left(\mu_{\alpha_{1}}, \mu_{\alpha_{2}}\right), \min \left(v_{\alpha_{1}}, v_{\alpha_{2}}\right)\right\}$;
(4) $\alpha_{1} \oplus \alpha_{2}=\left(\mu_{\alpha_{1}}+\mu_{\alpha_{2}}-\mu_{\alpha_{1}} \mu_{\alpha_{2}}, v_{\alpha_{1}} v_{\alpha_{2}}\right)$;
(5) $\alpha_{1} \otimes \alpha_{2}=\left(\mu_{\alpha_{1}} \mu_{\alpha_{2}}, v_{\alpha_{1}}+v_{\alpha_{2}}-v_{\alpha_{1}} v_{\alpha_{2}}\right)$;
(6) $\lambda \alpha=\left(1-\left(1-\mu_{\alpha}\right)^{\lambda}, v_{\alpha}^{\lambda}\right), \lambda>0$;
(7) $\alpha^{\lambda}=\left(\mu_{\alpha}^{\lambda}, 1-\left(1-v_{\alpha}\right)^{\lambda}\right), \lambda>0$. 
Based on the geometric distance model, $\mathrm{Xu}$ [17] proposed a distance measure formula of intuitionistic fuzzy set. The intuitionistic fuzzy integration operator is defined as follows:

Definition 3: Let $d$ be a mapping: $d:(\Phi(X))^{2} \rightarrow[0,1]$. If $\forall$ is the intuitionistic fuzzy set $A=\left\{\left\langle x, \mu_{A}(x), v_{A}(x)\right\rangle\right\}, B=\left\{\left\langle x, \mu_{B}(x), v_{B}(x)\right\rangle\right\}$ and $C=\left\{\left\langle x, \mu_{C}(x), v_{C}(x)\right\rangle\right\}$, then the distance measure formula is defined as follows:

$$
d_{X u}(A, B)=\left[\frac{1}{2 n} \sum_{j=1}^{n}\left(\left|\mu_{A}\left(x_{j}\right)-\mu_{B}\left(x_{j}\right)\right|^{\lambda}+\left|v_{A}\left(x_{j}\right)-v_{B}\left(x_{j}\right)\right|^{\lambda}+\left|\pi_{A}\left(x_{j}\right)-\pi_{B}\left(x_{j}\right)\right|^{\lambda}\right)\right]^{1 / \lambda}
$$

When $\lambda=1, d_{X u}$ is reduced to the Hamming distance:

$$
d_{\mathrm{H}}(A, B)=\frac{1}{2 n} \sum_{j=1}^{n}\left(\left|\mu_{A}\left(x_{j}\right)-\mu_{B}\left(x_{j}\right)\right|+\left|v_{A}\left(x_{j}\right)-v_{B}\left(x_{j}\right)\right|+\left|\pi_{A}\left(x_{j}\right)-\pi_{B}\left(x_{j}\right)\right|\right)
$$

When $\lambda=2, d_{X u}$ is reduced to the Euclidean distance:

$$
d_{\mathrm{E}}(A, B)=\sqrt{\frac{1}{2 n} \sum_{j=1}^{n}\left(\left|\mu_{A}\left(x_{j}\right)-\mu_{B}\left(x_{j}\right)\right|^{2}+\left|v_{A}\left(x_{j}\right)-v_{B}\left(x_{j}\right)\right|^{2}+\left|\pi_{A}\left(x_{j}\right)-\pi_{B}\left(x_{j}\right)\right|^{2}\right)}
$$

where all the distance measure formulas of intuitionistic fuzzy set satisfy:

(1) $0 \leq d(A, B) \leq 1$;

(2) When $A=B, d(A, B)=0$;

(3) $d(A, B)=d(B, A)$;

(4) If $A \subseteq B \subseteq C$, and $A, B, C \in \Phi(X)$, then $d(A, B) \leq d(A, C)$ and $d(B, C) \leq d(A, C)$.

In 2004, Grzegorzewski [18] proposed a distance measure formula of intuitionistic fuzzy set based on the Hausdorff measure which can be seen as the extension of the Hamming distance and the Euclidean distance.

Definition 4: Hausdorff measure-based Hamming distance:

$$
d_{H H}(A, B)=\frac{1}{n} \sum_{j=1}^{n} \max \left\{\left|\mu_{A}\left(x_{j}\right)-\mu_{B}\left(x_{j}\right)\right|,\left|v_{A}\left(x_{j}\right)-v_{B}\left(x_{j}\right)\right|\right\}
$$

Definition 5: Hausdorff measure-based Euclidean distance:

$$
d_{H \mathrm{E}}(A, B)=\frac{1}{n} \sum_{j=1}^{n} \max \left\{\left(\mu_{A}\left(x_{j}\right)-\mu_{B}\left(x_{j}\right)\right)^{2},\left(v_{A}\left(x_{j}\right)-v_{B}\left(x_{j}\right)\right)^{2}\right\}
$$

If this $\omega=\left(\omega_{1}, \omega_{2}, \ldots, \omega_{n}\right)^{T}$ be the weight vector of $x_{j}(j=1,2, \ldots, n), \omega_{j} \geq 0 \quad(j=1,2, \ldots, n)$ and $\sum_{j=1}^{n} \omega_{j}=1$, then eqs. (3) to (6) can be transformed as follows:

$$
\begin{gathered}
d_{\mathrm{H}}(A, B)=\frac{1}{2 n} \sum_{j=1}^{n} \omega_{j}\left(\left|\mu_{A}\left(x_{j}\right)-\mu_{B}\left(x_{j}\right)\right|+\left|v_{A}\left(x_{j}\right)-v_{B}\left(x_{j}\right)\right|+\left|\pi_{A}\left(x_{j}\right)-\pi_{B}\left(x_{j}\right)\right|\right) \\
d_{\mathrm{E}}(A, B)=\sqrt{\frac{1}{2 n} \sum_{j=1}^{n} \omega_{j}\left(\left|\mu_{A}\left(x_{j}\right)-\mu_{B}\left(x_{j}\right)\right|^{2}+\left|v_{A}\left(x_{j}\right)-v_{B}\left(x_{j}\right)\right|^{2}+\left|\pi_{A}\left(x_{j}\right)-\pi_{B}\left(x_{j}\right)\right|^{2}\right)} \\
d_{H H}(A, B)=\frac{1}{n} \sum_{j=1}^{n} \omega_{j} \max \left\{\left|\mu_{A}\left(x_{j}\right)-\mu_{B}\left(x_{j}\right)\right|, \mid v_{A}\left(x_{j}\right)-v_{B}\left(x_{j}\right)\right\} \\
d_{H \mathrm{E}}(A, B)=\frac{1}{n} \sum_{j=1}^{n} \omega_{j} \max \left\{\left(\mu_{A}\left(x_{j}\right)-\mu_{B}\left(x_{j}\right)\right)^{2},\left(v_{A}\left(x_{j}\right)-v_{B}\left(x_{j}\right)\right)^{2}\right\}
\end{gathered}
$$




\subsection{TODIM method based on prospect theory}

TODIM (Portuguese: Tomada de Decisao Interativa Multicriterio) is a multiple attribute decision making method based on prospect theory proposed by Gomes and Lima [19] in 1992. Differing from the traditional decision-making method of "rational man", TODIM is based on the hypothesis of "limited rational man", meaning it considers the psychological behaviour of decision makers. It does not obey the expected utility maximization principle and it aims to help people make satisfactory decisions more effectively whilst minimising risk. For better understanding of the TODIM method, we first introduce its theoretical basis: prospect theory.

The prospect theory put forward by Kahneman and Tversky [20] has corrected traditional decision-making and expected utility theory and has been the basis for a new decision-making framework model, which assumes that the risk decision-making process is divided into two stages: editing and evaluation. In the editing stage, the information is collected and processed according to "frame", "reference point", etc. In the evaluation stage, the information is determined by the value function and the weighting function of subjective probability. It also explains how the value function changes in a "S" shape when people dealing with benefit and the loss, as shown in Fig. 2. As the proposed expectation value theory leads to huge contributions to the field of risk decision, Kahneman won the 2002 Nobel Prize in economics.

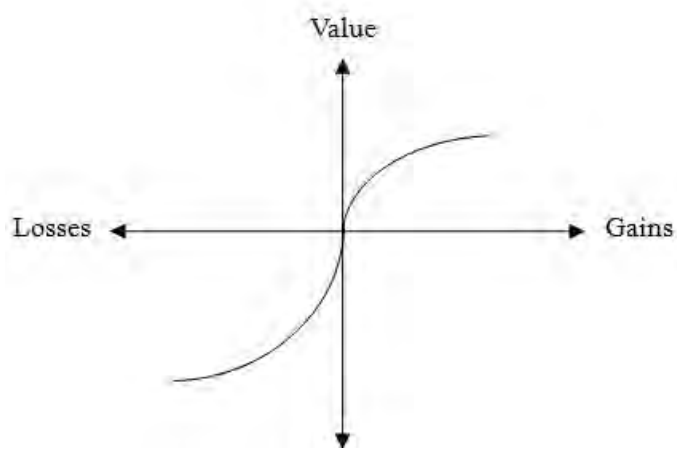

Figure 2: The prospect value function.

In prospect theory, the prospect value is determined by the value function and weight function, namely:

$$
V=\sum v(x) \pi(p)
$$

where $v(x)$ denotes the value function, meaning the values are caused by the subjective feelings of decision makers according to the actual gains or losses, and $\pi(p)$ denotes the decision weighting function:

$$
v(x)=\left\{\begin{array}{cc}
x^{\alpha}, & x \geq 0 \\
-\delta(-x)^{\beta}, & x<0
\end{array}\right.
$$

In the formula above, $x \geq 0$ means gains; $x<0$ means losses. $\alpha$ and $\beta$ denote respectively the concave and convex degree in the gains and losses area, which can reflect the sensitivity degree of the decision-makers to the gains and losses. The weighting function is defined as follows:

$$
\pi(p)=\left\{\begin{array}{l}
\pi^{+}(p)=\frac{p^{\xi}}{\left(p^{\xi}+(1-p)^{\xi}\right)^{1 / \xi}} \\
\pi^{-}(p)=\frac{p^{\tau}}{\left(p^{\tau}+(1-p)^{\tau}\right)^{1 / \tau}}
\end{array}\right.
$$

where $p$ denotes the probability, $\xi$ and $\tau$ denote the change of the weighting function. The weighting function also shows how different attitudes of the decision-makers can lead to 
gains and the losses. There are 5 parameters in the value function and the weighting function of prospect theory, $\alpha, \beta, \delta, \xi$ and $\tau$.

The basic principle of TODIM is to establish the dominance matrix composed of multiple comparisons of alternatives. By aggregating the dominance of each evaluation alternative and sorting the alternatives, the overall advantages can be obtained. The decisionmaking steps are as follows:

Step 1: Standardize the decision-making matrix $X=\left[x_{i j}\right]_{m \times n}$ into the standard matrix $Y=\left[y_{i j}\right]_{m \times n}$.

Step 2: Calculate the gain and loss decision matrix $Z=\left[z_{i k}^{j}\right]_{m \times m}$ under each attribute $C_{j}$, where $z_{i k}^{j}$ denotes the relative degree of gain and loss of the compared attribute values $y_{i j}$ and $y_{k j}$. The eq. is defined as follows:

$$
z_{i k}^{j}=\left\{\begin{array}{cl}
d_{i k}^{j}, & y_{i j} \geq y_{k j} \\
-d_{i k}^{j}, & y_{i j}<y_{k j}
\end{array} \quad i \in N ; k \in N ; i \in M\right.
$$

Step 3: Calculate the relative weight $\omega_{j}^{\prime}$ of each attribute relative to the reference attribute. The eq. is defined as follows:

$$
\omega_{j}{ }^{\prime}=\omega_{j} / \omega_{\max }, i \in N
$$

Step 4: Calculate the dominance $\rho^{j}\left(A_{i}, A_{k}\right)$ of alternative $A_{i}$ relative to alternative $A_{k}$ under attribute $C_{j}$. The eq. is defined as follows:

$$
\rho^{j}\left(A_{i}, A_{k}\right)=\left\{\begin{array}{cl}
\sqrt{z_{i k}^{j} \omega_{j}^{\prime} /\left(\sum_{j=1}^{n} \omega_{j}{ }^{\prime}\right)}, & y_{i j} \geq y_{k j} \\
-\frac{1}{\theta} \sqrt{z_{i k}^{j}\left(\sum_{j=1}^{n} \omega_{j}{ }^{\prime}\right) / \omega_{j}^{\prime}}, & y_{i j}<y_{k j}
\end{array} \quad j \in N ; k \in N ; i \in M\right.
$$

Establish the dominance matrix $\mathrm{P}^{j}=\left[\rho^{j}\left(A_{i}, A_{k}\right)\right]_{m \times m}$ under attribute $C_{j}$. In the eq. above, $\theta$ denotes the loss aversion coefficient, $0<\theta<\left(\sum_{j=1}^{n} \omega_{j}{ }^{\prime}\right) / \omega_{j}{ }^{\prime}[21]$. The smaller the $\theta$, the higher the risk aversion. Obviously, there are such relations:

$$
\left|\sqrt{z_{i k}^{j} \omega_{j}^{\prime} /\left(\sum_{j=1}^{n} \omega_{j}{ }^{\prime}\right)}\right|<\left|-\frac{1}{\theta} \sqrt{z_{i k}^{j}\left(\sum_{j=1}^{n} \omega_{j}{ }^{\prime}\right) / \omega_{j}{ }^{\prime}}\right|
$$

These show that the decision-makers are more sensitive to the latter in the face of gains and losses with the same absolute value, and thus the decision-makers exhibit loss aversion.

Step 5: Calculate the overall dominance $\rho\left(A_{i}, A_{k}\right)$ of alternative $A_{i}$ relative to alternative $A_{k}$. The eq. is defined as follows:

$$
\rho\left(A_{i}, A_{k}\right)=\sum_{j=1}^{n} \rho^{j}\left(A_{i}, A_{k}\right) \quad j \in N ; k \in N
$$

Step 6: Calculate the overall dominance $S\left(A_{i}\right)$ of alternative $A_{i}$ relative to other alternatives. The eq. is defined as follows:

$$
S\left(A_{i}\right)=\frac{\sum_{k=1}^{m} \rho\left(A_{i}, A_{k}\right)-\min _{1 \leq i \leq m}\left\{\sum_{k=1}^{m} \rho\left(A_{i}, A_{k}\right)\right\}}{\max _{1 \leq i \leq m}\left\{\sum_{k=1}^{m} \rho\left(A_{i}, A_{k}\right)\right\}-\min _{1 \leq i \leq m}\left\{\sum_{k=1}^{m} \rho\left(A_{i}, A_{k}\right)\right\}} \quad i \in N ; k \in N ; i \in M
$$

Sort the alternatives according to $S\left(A_{i}\right)$. 


\subsection{The establishment and decision-making process of a distributor evaluation and selection model based on IF-TODIM}

Suppose in a production enterprise, $m$ distributors to be evaluated compose alternative sets $A=\left\{A_{1}, A_{2}, \cdots, A_{m}\right\}$, the evaluation indicator sets are attribute sets $C=\left\{C_{1}, C_{2}, \cdots, C_{n}\right\}$, and the weight vector of the indicators is $\omega=\left(\omega_{1}, \omega_{2}, \cdots, \omega_{n}\right)^{T}$, where $\sum_{j=1}^{n} \omega_{j}=1, \omega_{j} \in[0,1]$, $(j=1,2, \ldots, n) . \mu_{i j} \in[0,1]$ denotes the satisfaction degree of $A_{i}$ about $C_{j}$, and $v_{i j} \in[0,1]$ denotes the dissatisfaction degree of $A_{i}$ about $C_{j}$, where $0 \leq \mu_{i j}+v_{i j} \leq 1$. In this way, the intuitionistic fuzzy number $x_{i j}=\left(\mu_{i j}, v_{i j}\right)$ denotes the evaluation value of $A_{i}(i=1,2, \ldots, m)$ under $C_{j}$ $(j=1,2, \ldots, n)$. As a result, the distributor evaluation and selection problem based on intuitionistic fuzzy - TODIM can be defined as the decision-making matrix $X=\left(x_{i j}\right)_{m \times n}$, which is shown in Table II.

Table II: Intuitionistic fuzzy decision matrix.

\begin{tabular}{|c|c|c|c|c|}
\hline & $C_{1}$ & $C_{2}$ & $\cdots$ & $C_{n}$ \\
\hline$A_{1}$ & $\left(\mu_{11}, v_{11}\right)$ & $\left(\mu_{12}, v_{12}\right)$ & $\cdots$ & $\left(\mu_{1 n}, v_{1 n}\right)$ \\
\hline$A_{2}$ & $\left(\mu_{21}, v_{21}\right)$ & $\left(\mu_{22}, v_{22}\right)$ & $\cdots$ & $\left(\mu_{2 n}, v_{2 n}\right)$ \\
\hline$\vdots$ & $\vdots$ & $\vdots$ & $\cdots$ & $\vdots$ \\
\hline$A_{m}$ & $\left(\mu_{m 1}, v_{m 1}\right)$ & $\left(\mu_{m 2}, v_{m 2}\right)$ & $\cdots$ & $\left(\mu_{m n}, v_{m n}\right)$ \\
\hline
\end{tabular}

This paper starts by collecting the distributors' information, aggregating the subjective evaluation given by the invited experts into the attribute values, and finally evaluating and selecting the optimal distributors based on prospect theory and the TODIM method. The evaluation process is shown in Fig. 3.

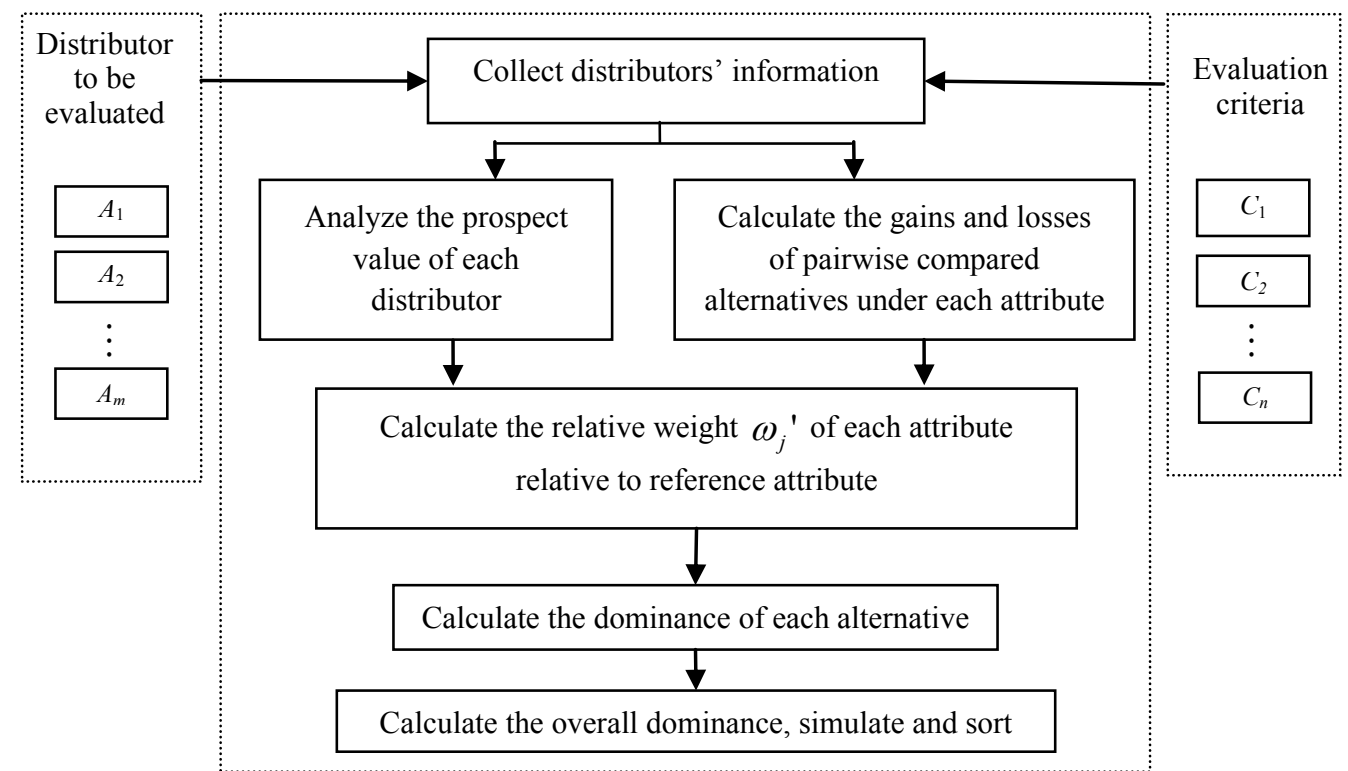

Figure 3: Distributor evaluation and selection flow chart based on IF-TODIM.

\section{NUMERICAL EXAMPLE AND SIMULATION ANALYSIS}

In this example, the aim was to select the appropriate distributor for an electrical appliances production enterprise. There were 5 target distributors, namely, $A=\left\{A_{1}, A_{2}, \ldots, A_{5}\right\}$. The 
primary indicators are shown in Table I, namely, $C=\left\{C_{1}, C_{2}, \ldots, C_{6}\right\}$ and the secondary indicators are the scoring reference for the evaluation experts. The experts group consisting of 4 members decided to adopt the normal empowerment method [22] to empower the 6 evaluation indicators after consulting where:

$$
\omega=(0.0865,0.1716,0.2419,0.2419,0.1716,0.0865)^{T} .
$$

Through synthesis scoring by the evaluation group, the evaluation matrix is established in which the attribute values are intuitionistic fuzzy numbers as shown in Table III.

Table III: Intuitionistic fuzzy decision matrix.

\begin{tabular}{|c|c|c|c|c|c|c|}
\hline & $C_{1}$ & $C_{2}$ & $C_{3}$ & $C_{4}$ & $C_{5}$ & $C_{6}$ \\
\hline$A_{1}$ & $(0.73,0.19)$ & $(0.72,0.10)$ & $(0.65,0.35)$ & $(0.72,0.27)$ & $(0.72,0.18)$ & $(0.81,0.19)$ \\
\hline$A_{2}$ & $(0.22,0.50)$ & $(0.16,0.83)$ & $(0.18,0.80)$ & $(0.23,0.70)$ & $(0.24,0.75)$ & $(0.22,0.73)$ \\
\hline$A_{3}$ & $(0.45,0.35)$ & $(0.64,0.15)$ & $(0.55,0.30)$ & $(0.46,0.46)$ & $(0.47,0.16)$ & $(0.47,0.38)$ \\
\hline$A_{4}$ & $(0.35,0.40)$ & $(0.36,0.30)$ & $(0.36,0.46)$ & $(0.50,0.20)$ & $(0.49,0.21)$ & $(0.55,0.30)$ \\
\hline$A_{5}$ & $(0.52,0.19)$ & $(0.42,0.18)$ & $(0.43,0.42)$ & $(0.55,0.35)$ & $(0.50,0.10)$ & $(0.55,0.16)$ \\
\hline
\end{tabular}

In the CPFR process of the supply chain, the electrical appliances production enterprise hoped to seek a distributor for long-term cooperation and an excellent multi-channel distributor. We then calculated and simulated the evaluation process according to the intuitionistic fuzzy TODIM model established above. Firstly, we analysed the prospect value of the result that the experts evaluated according to eqs. (11) to (13). Tversky and Kahneman [20] carried out a large number of experiments and achieved the results $\alpha=\beta=0.88, \xi=0.61$, $\tau=0.69$. In this paper, we simulated the distributor evaluation results that came from the experts into prospect values, and let $\delta=1, \delta=2.5$. The prospect value function curves are shown as follows:

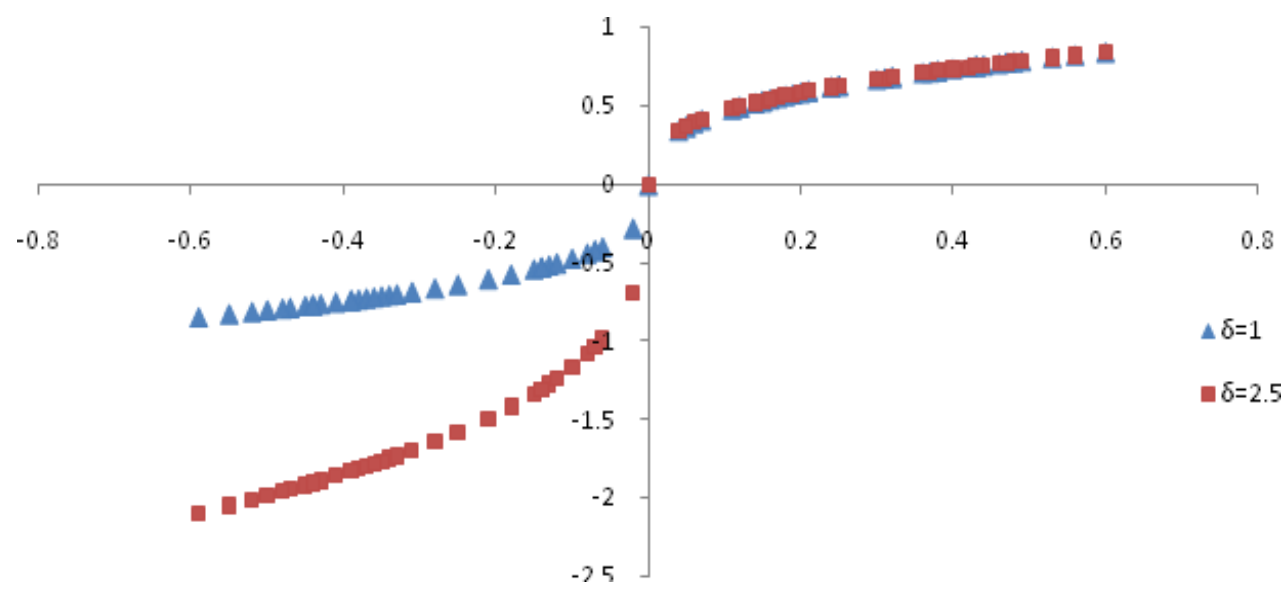

Figure 4: Prospect value function curves when parameter $\delta=1$ and $\delta=2.5$.

When $\delta=1$ and $\delta=2.5$ in the gain quadrant, the prospect value curves of the two parameters basically coincide; when $\delta=1$ in the loss quadrant, the curve seems more inclined than when $\delta=2.5$. This shows two aspects of the situation: one is that decision-makers get more and more sensitive to the variation of the risk with the decrease of the risk aversion parameter (in fact decision-makers on the risk of loss aversion is improving); the other is that people are not as sensitive to the gains variation as the loss, so comparing to the positive evaluation at the distributor selection, the manufacturer pays more attention to the negative evaluation values, which is consistent with the actual decision-making requirements. 
The gain and loss of the compared attributes under attribute $C_{j}$ was calculated according to the intuitionistic fuzzy distance measure eqs. (3) to (6). Next to be calculated was the overall dominance of each distributor to be evaluated relative to other distributors. As the TODIM method fully considers the psychological behaviour change of the decision-makers, we simulated the calculating process. Respectively let $\theta=0.3,0.8,1.0,2.5,3.0,4.0$. The dominance variation of each distributor to be evaluated is shown in Fig. 5:

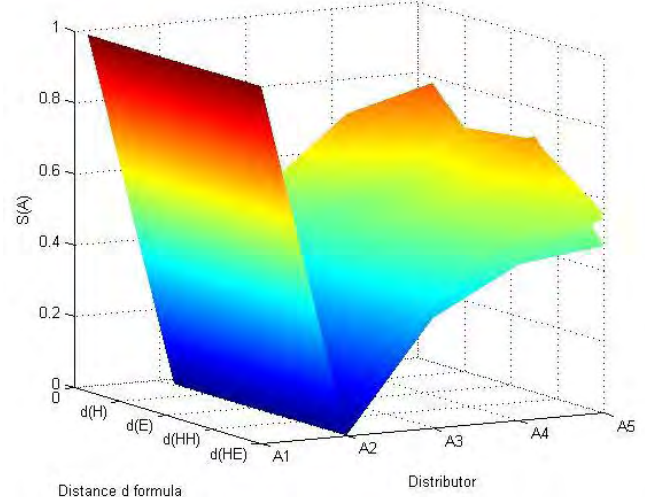

a) $\theta=0.3$

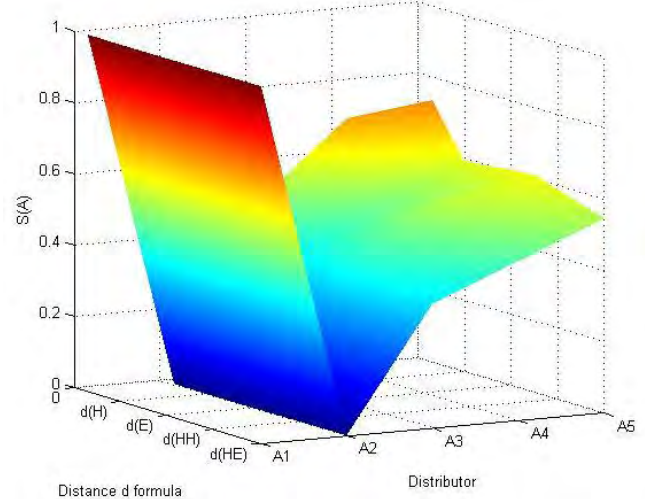

c) $\theta=1.0$

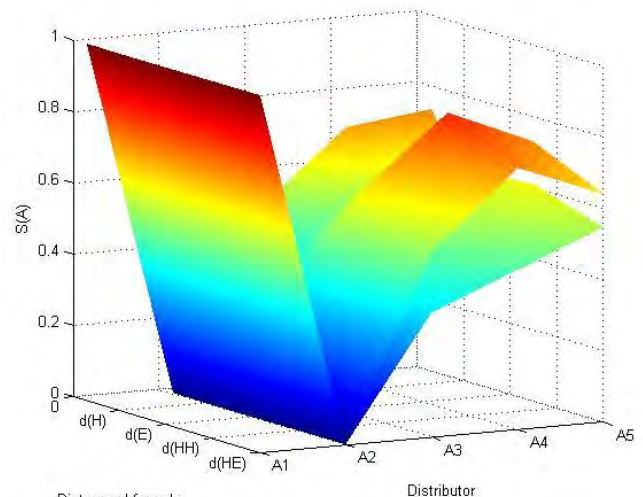

e) $\theta=3.0$

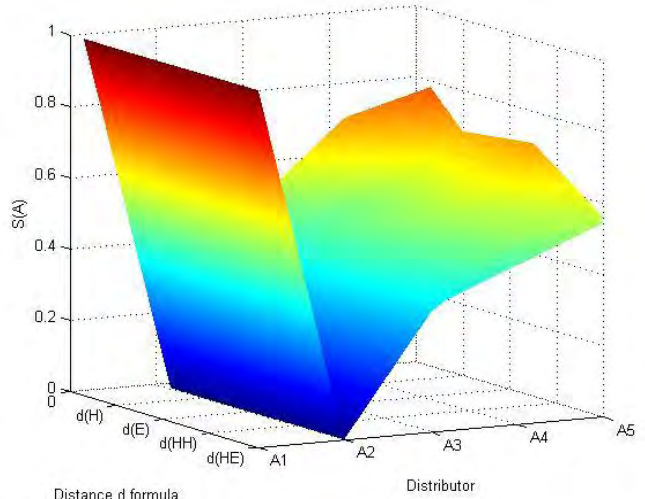

b) $\theta=0.8$

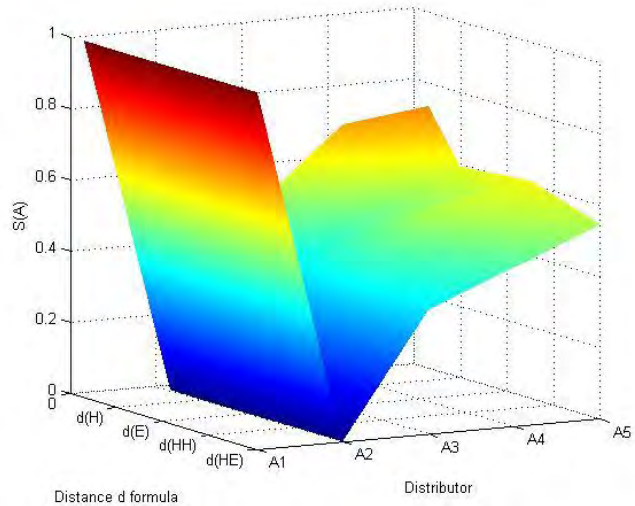

d) $\theta=2.5$

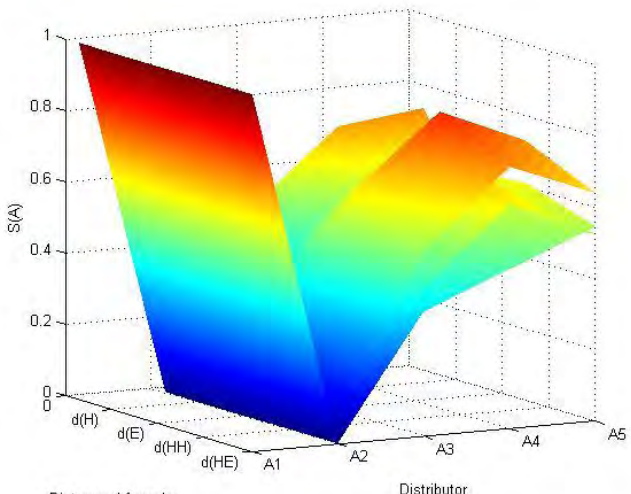

f) $\theta=4.0$

Figure 5: The space curved surfaces of distributor dominance in the four distance equations when parameter $\theta$ varies.

As seen from Fig. 5, the dominance of distributors $A_{1}$ and $A_{2}$ was stable, and the dominance of distributors $A_{3}, A_{4}$ and $A_{5}$ was instable as the parameter $\theta$ varied. The variation trend is shown in Table IV. 
Table IV: The comparison results of the distributor dominance in the four distance equations when parameter $\theta$ varies.

\begin{tabular}{|c|c|c|c|c|}
\hline Parameter $\theta$ & $\begin{array}{l}\text { Intuitionistic fuzzy } \\
\text { distance measure }\end{array}$ & Dominance result & $\begin{array}{l}\text { The selected } \\
\text { distributors }\end{array}$ & $\begin{array}{c}\text { The discarded } \\
\text { distributors }\end{array}$ \\
\hline \multirow{4}{*}{$\theta=0.3$} & $d_{H}$ & $(1.000,0.000,0.517,0.715,0.751)$ & $A_{1} A_{5}$ & $A_{2}$ \\
\hline & $d_{E}$ & $(1.000,0.000,0.332,0.505,0.643)$ & $A_{1} A_{5}$ & $A_{2}$ \\
\hline & $d_{H H}$ & $(1.000,0.000,0.406,0.519,0.718)$ & $A_{1} A_{5}$ & $A_{2}$ \\
\hline & $d_{H E}$ & $(1.000,0.000,0.307,0.438,0.468)$ & $A_{1} A_{5}$ & $A_{2}$ \\
\hline \multirow{4}{*}{$\theta=0.8$} & $d_{H}$ & $(1.000,0.000,0.504,0.717,0.782)$ & $A_{1} A_{5}$ & $A_{2}$ \\
\hline & $d_{E}$ & $(1.000,0.000,0.424,0.517,0.684)$ & $A_{1} A_{5}$ & $A_{2}$ \\
\hline & $d_{H H}$ & $(1.000,0.000,0.405,0.550,0.708)$ & $A_{1} A_{5}$ & $A_{2}$ \\
\hline & $d_{H E}$ & $(1.000,0.000,0.337,0.507,0.558)$ & $A_{1} A_{5}$ & $A_{2}$ \\
\hline \multirow{4}{*}{$\theta=1.0$} & $d_{H}$ & $(1.000,0.000,0.499,0.704,0.734)$ & $A_{1} A_{5}$ & $A_{2}$ \\
\hline & $d_{E}$ & $(1.000,0.000,0.357,0.474,0.590)$ & $A_{1} A_{5}$ & $A_{2}$ \\
\hline & $d_{H H}$ & $(1.000,0.000,0.401,0.555,0.608)$ & $A_{1} A_{5}$ & $A_{2}$ \\
\hline & $d_{H E}$ & $(1.000,0.000,0.349,0.447,0.546)$ & $A_{1} A_{5}$ & $A_{2}$ \\
\hline \multirow{4}{*}{$\theta=2.5$} & $d_{H}$ & $(1.000,0.000,0.468,0.719,0.659)$ & $A_{1} A_{4}$ & $A_{2}$ \\
\hline & $d_{E}$ & $(1.000,0.000,0.313,0.553,0.449)$ & $A_{1} A_{4}$ & $A_{2}$ \\
\hline & $d_{H H}$ & $(1.000,0.000,0.354,0.593,0.553)$ & $A_{1} A_{4}$ & $A_{2}$ \\
\hline & $d_{H E}$ & $(1.000,0.000,0.385,0.501,0.498)$ & $A_{1} A_{4}$ & $A_{2}$ \\
\hline \multirow{4}{*}{$\theta=3.0$} & $d_{H}$ & $(1.000,0.000,0.460,0.689,0.587)$ & $A_{1} A_{4}$ & $A_{2}$ \\
\hline & $d_{E}$ & $(1.000,0.000,0.381,0.593,0.520)$ & $A_{1} A_{4}$ & $A_{2}$ \\
\hline & $d_{H H}$ & $(1.000,0.000,0.631,0.831,0.729)$ & $A_{1} A_{4}$ & $A_{2}$ \\
\hline & $d_{H E}$ & $(1.000,0.000,0.521,0.732,0.639)$ & $A_{1} A_{4}$ & $A_{2}$ \\
\hline \multirow{4}{*}{$\theta=4.0$} & $d_{H}$ & $(1.000,0.000,0.445,0.702,0.663)$ & $A_{1} A_{4}$ & $A_{2}$ \\
\hline & $d_{E}$ & $(1.000,0.000,0.301,0.530,0.528)$ & $A_{1} A_{4}$ & $A_{2}$ \\
\hline & $d_{H H}$ & $(1.000,0.000,0.460,0.713,0.500)$ & $A_{1} A_{4}$ & $A_{2}$ \\
\hline & $d_{H E}$ & $(1.000,0.000,0.412,0.632,0.521)$ & $A_{1} A_{4}$ & $A_{2}$ \\
\hline
\end{tabular}

We can draw two conclusions from the simulation. Firstly, the classic intuitionistic fuzzy distance measure formula is robust with respect to the TODIM decision result. In other words, if parameter $\theta$ is fixed, any distance formula we choose will not have any influence to the final evaluation result. Secondly, the selected distributor will obviously change as parameter $\theta$ changes, i.e., as the risk aversion coefficient of decision-makers changes. When $\theta$ is a small value, the distributors $A_{1}$ and $A_{5}$ are selected; when $\theta$ gets higher, distributors $A_{1}$ and $A_{4}$ are selected. This has practical significance to the distributor selection in the CPFR process in real life. Manufacturers in growth and recession have a weaker ability to resist the market risk ability, so $\theta$ should be higher when using an IF-TODIM model. Conversely, manufacturers in development and maturity have a stronger ability, so $\theta$ should be lower. The result shows that the IF-TODIM model is effective and the distributor evaluation and selection is easily computed.

\section{CONCLUSION}

In the CPFR process of supply chain, manufacturers can improve the partnership with distributors and suppliers by means of the collaborative management of business and information sharing. Distributors, as the leading "tie" between manufacturers and customers, collect marketing information, decrease the uncertainty of demand and improve the customers' satisfaction. In the CPFR process, reasonable evaluation and selection of the distributors can ensure smooth distribution channels in the CPFR process, so that the competitiveness of the whole supply chain can be increased.

In this paper, the main innovations of the model based on the evaluation and selection of the distributor can be embodied in the following four aspects. Firstly, we introduced an 
evaluation method which includes intuitionistic fuzzy numbers. On the one hand, the intuitionistic fuzzy number data type is better than fuzzy number, real number or language in describing the uncertainty of data. In the process of selecting the distributor for the upstream enterprises, there are a lot of uncertain evaluation values, which could be better evaluated with this data type. On the other hand, using the TODIM decision-making method as the core of the model needs to be standardized, and because the intuitionistic fuzzy number range is between 0 and 1 , and it does not need to be standardized. This natural advantage means that the computational complexity can be greatly reduced and the accuracy of the results will be increased. Secondly, there is great competition to introduce the TODIM decision method to the distributor selection field. The advantage of this method is that it takes into account the psychological behaviour of the decision makers and, compared to those decision making methods based on the "expected utility value", this method has more value in practical application. Thirdly, in the model calculation, we introduced four distance formulas of intuitionistic fuzzy set measure, carried out the comparative analysis, and then displayed the data relationship among the evaluation values more completely, avoiding the deviation caused by the improper selection of distance formula. Finally, the different values of the loss aversion coefficient based on TODIM was simulated, which shows the change process and trend of the final selection when the manufacturers are in different psychological risk states.

\section{ACKNOWLEDGEMENT}

This paper was supported by the National Natural Science Foundation of China (71271070), Specialty of College Comprehensive Reform Pilot Project (ZG0429) and Specialty and curriculum integration project of Guangxi high school (GXTSZY016).

\section{REFERENCES}

[1] Rosenbloom, B. (2003). Marketing Channels: A Management View, $7^{\text {th }}$ ed., South-Western College Publishing, Mason

[2] Mohr, J.; Nevin, J. R. (1990). Communication strategies in marketing channels: a theoretical perspective, Journal of Marketing, Vol. 54, No. 4, 36-51, doi:10.2307/1251758

[3] Jonsson, P.; Zineldin, M. (2003). Achieving high satisfaction in supplier-dealer working relationships, Supply Chain Management: An International Journal, Vol. 8, No. 3, 224-240, doi: $10.1108 / 13598540310484627$

[4] Lin, J.-S. C.; Chen, C.-R. (2008). Determinants of manufacturers' selection of distributors, Supply Chain Management: An International Journal, Vol. 13, No. 5, 356-365, doi:10.1108/ 13598540810894942

[5] Humphreys, P.; McCloskey, A.; McIvor, R.; Maguire, L.; Glackin, C. (2006). Employing dynamic fuzzy membership functions to assess environmental performance in the supplier selection process, International Journal of Production Research, Vol. 44, No. 12, 2379-2419, doi: $10.1080 / 00207540500357476$

[6] Shen, L.; Olfat, L.; Govindan, K.; Khodaverdi, R.; Diabat, A. (2013). A fuzzy multi criteria approach for evaluating green supplier's performance in green supply chain with linguistic preferences, Resources, Conservation and Recycling, Vol. 74, 170-179, doi:10.1016/j.resconrec. $\underline{2012.09 .006}$

[7] Humphreys, P.; McIvor, R.; Chan, F. (2003). Using case-based reasoning to evaluate supplier environmental management performance, Expert Systems with Applications, Vol. 25, No. 2, 141 153, doi:10.1016/S0957-4174(03)00042-3

[8] Zou, Z.; Tseng, T. L.; Sohn, H.; Song, G.; Gutierrez, R. (2011). A rough set based approach to distributor selection in supply chain management, Expert Systems with Applications, Vol. 38, No. 1, 106-115, doi:10.1016/j.eswa.2010.06.021 
[9] Ghorbani, M.; Arabzad, S. M.; Bahrami, M. (2012). Applying a neural network algorithm to distributor selection problem, Procedia - Social and Behavioral Sciences, Vol. 41, 498-505, doi: $10.1016 /$ j.sbspro.2012.04.061

[10] Bai, C.; Sarkis, J. (2010). Green supplier development: analytical evaluation using rough set theory, Journal of Cleaner Production, Vol. 18, No. 12, 1200-1210, doi:10.1016/j.jclepro. 2010.01.016

[11] Kuo, R. J.; Lin, Y. J. (2012). Supplier selection using analytic network process and data envelopment analysis, International Journal of Production Research, Vol. 50, No. 11, 2852-2863, doi: $10.1080 / 00207543.2011 .559487$

[12] Kuo, R. J.; Wang, Y. C.; Tien, F. C. (2010). Integration of artificial neural network and MADA methods for green supplier selection, Journal of Cleaner Production, Vol. 18, No. 12, 1161-1170, doi:10.1016/j.jclepro.2010.03.020

[13] Atanassov, K. T. (1986). Intuitionistic fuzzy sets, Fuzzy Sets and Systems, Vol. 20, No. 1, 87-96, doi:10.1016/S0165-0114(86)80034-3

[14] Atanassov, K. T. (1989). More on intuitionistic fuzzy sets, Fuzzy Sets and Systems, Vol. 33, No. 1, 37-45, doi:10.1016/0165-0114(89)90215-7

[15] Zadeh, L. A. (1965). Fuzzy sets, Information and Control, Vol. 8, No. 3, 338-353, doi:10.1016/S0019-9958(65)90241-X

[16] Atanassov, K. T. (1994). New operations defined over the intuitionistic fuzzy sets, Fuzzy Sets and Systems, Vol. 61, No. 2, 137-142, doi:10.1016/0165-0114(94)90229-1

[17] Xu, Z. S. (2007). Some similarity measures of intuitionistic fuzzy sets and their applications to multiple attribute decision making, Fuzzy Optimization and Decision Making, Vol. 6, No. 2, 109121, doi:10.1007/s10700-007-9004-Z

[18] Grzegorzewski, P. (2004). Distances between intuitionistic fuzzy sets and/or interval-valued fuzzy sets based on the Hausdorff metric, Fuzzy Sets and Systems, Vol. 148, No. 2, 319-328, doi:10.1016/j.fss.2003.08.005

[19] Gomes, L. F. A. M.; Lima, M. M. P. P. (1992). TODIM: Basics and application to multicriteria ranking of projects with environmental impacts, Foundations of Computing and Decision Sciences, Vol. 16, No. 4, 113-127

[20] Tversky, A.; Kahneman, D. (1992). Advances in prospect theory: Cumulative representation of uncertainty, Journal of Risk and Uncertainty, Vol. 5, No. 4, 297-323, doi:10.1007/BF00122574

[21] Lahdelma, R.; Salminen, P. (2009). Prospect theory and stochastic multicriteria acceptability analysis (SMAA), Omega, Vol. 37, No. 5, 961-971, doi:10.1016/j.omega.2008.09.001

[22] Xu, Z. S. (2005). An overview of methods for determining OWA weights, International Journal of Intelligent Systems, Vol. 20, No. 8, 843-865, doi:10.1002/int.20097 